\title{
Conformation and supramolecular arrangement of 1,3:2,4-dibenzyli- dene-D-sorbitol in solution and in single crystals
}

\author{
Fernán Berride, ${ }^{\#}$ Víctor M. Sánchez-Pedregal, ${ }^{+}$Bruno Dacuña, ${ }^{\ddagger}$ Eurico Cabrita, \& Armando Navarro-Váz- \\ quez, $^{*, s}$ Richard G. Weiss*,s and María Magdalena Cid*,\# \\ \# Departamento de Química Orgánica, Universidade de Vigo, 36310 Vigo, Spain \\ † Departamento de Química Orgánica, Universidade de Santiago de Compostela, 15782 Santiago de Compostela, Spain \\ ‡ Servizo Raios-X, RAIDT, Universidade de Santiago de Compostela, 15782 Santiago de Compostela, Spain \\ \& Departamento de Química e CIBIO, Faculdade de Ciências e Tecnologia, Universidade Nova de Lisboa, 2829-516 Caparica, Portugal \\ \$ Departamento de Química Fundamental, Centro de Ciências Exatas e da Natureza, Universidade Federal de Pernambuco, Cidade Universitária - Recife, \\ $\mathrm{PE}$, 50740-540, Brazil \\ $\S$ Department of Chemistry and Institute for Soft Matter Synthesis and Metrology, Georgetown University, Washington, DC 20057-1227, United States
}

\section{$D B S \bullet$ gelification $\bullet$ crystal structure •supramolecular arrangement $\bullet M R$}

\begin{abstract}
The X-ray crystal structure of the gelator 1,3:2,4-dibenzylidene-D-sorbitol (DBS) is reported here. DBS is an important gelating molecule known for nearly 130 years, that has eluded crystallization until now. The crystal obtained presents an axial stacking of DBS molecules stabilized by both Van der Waals interactions and intermolecular hydrogen bonds of the side chain hydroxyl groups with either neighboring DBS or water molecules. The crystal structure shows definitive evidence for the frequently assumed "butterfly" type aggregation mode and experimentally proves the equatorial placement of the phenyl rings. The conformation of DBS has been analyzed in the crystal structure and compared with that determined in solution through NMR spectroscopy.
\end{abstract}

\section{Introduction}

1,3:2,4-dibenzylidene-D-sorbitol (DBS) ${ }^{[1]}$ (Scheme 1, 2) can be considered the archetype of a classic low molecular weight gelator (LMWG), which has presented enigmatic structural challenges for nearly 130 years. ${ }^{[2]}$ Despite its long history, DBS still remains an important topic of investigation in the field of gel research.

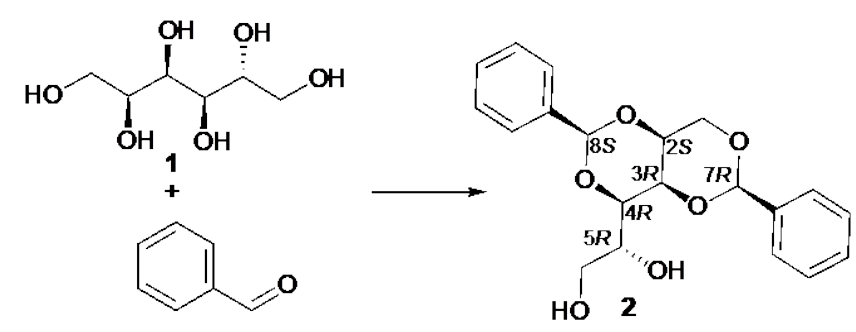

DBS is obtained by condensation of D-sorbitol 1 with two equivalents of benzaldehyde. The $(2 S, 3 R, 4 R, 5 R)-2$ diastereomer is obtained in the condensation rather than the $(2 R, 3 R, 4 R, 5 R)$ form as already shown in 1942 by Wolfe and coworkers ${ }^{[1]}$ through chemical derivatization. Today, these two structures can be easily distinguished by measuring the NMR scalar coupling between the protons at positions $\mathrm{C} 2$ and C3. The configuration of DBS 2 at the benzylic positions $\mathrm{C} 7$ and $\mathrm{C} 8$ had been assumed in the literature to be $7 R, 8 S$ in terms of thermodynamic stability rather than experimental evidence. Recently, we experimentally determined such configurations by NMR spectroscopy supported by rigorous computer calculations. ${ }^{[3]}$

The combination of hydrophobic phenyl rings and hydroxyl groups makes DBS an amphiphilic molecule that self-assembles into three-dimensional nanofibrillar networks at low concentrations to produce organogels ${ }^{[4]}$ in a variety of solvents, ${ }^{[5][6]}$ polymers, ${ }^{[7][8][9][10]}$ deep eutectic solvents, ${ }^{[11]}$ /yotropic liquid crystals ${ }^{[12]}$ and ionic liquids. ${ }^{[13]}$ Depending on the solvent and the DBS concentration, the gels vary from being transparent at low concentrations in solvents like acetone and isopropyl alcohol, to murkywhitish at higher DBS concentrations or in solvents such as ethyl acetate and toluene. ${ }^{[5][14]}$ Electron microscopy studies of gels formed in acetone and benzene show the presence of rigid, helically-twisted nanofibrils ( $15-30 \mathrm{~nm}$ in diameter) in both gel and xerogel phases of DBS. ${ }^{[15]}$ The fibers have a well-defined helicity with a periodicity of $\sim 45 \mathrm{~nm}$. Solid-state NMR studies ${ }^{[15]}$ showed very similar ${ }^{13} \mathrm{C}$ chemical shifts for gel and melted-crystallized samples, suggesting that gels and crystalline sample should share a similar stacking motif at the atomic level.

Although X-ray crystal structures of molecules derived from DBS are known, ${ }^{[16][17][18][19][20][21] ~ n o n e ~ u n t i l ~ n o w ~ h a s ~ b e e n ~ r e p o r t e d ~ f o r ~}$ DBS itself. The lack of one can be understood in large part due to the propensity of DBS to form gels in many liquids, even at low concentrations. Diffraction quality crystals are exceedingly difficult to obtain from such gels.

The initial steps in the phase separation of small molecular gelators, like DBS (topologically OD objects on a submicron distance scale), in their sol phases lead usually in their eventual gel structures to topologically $1 \mathrm{D}$ objects with lengths in the micron range and very large aspect ratios. ${ }^{[10][22][23][24][25]}$ The propensity of DBS molecules to self-assemble in a wide variety of solvents has been ascribed to its "butterfly-like" shape, in which the benzylidene groups constitute the hydrophobic "wings" and the sorbitol skeleton the hydrophilic "body". Results from different spectroscopic techniques, along with theoretical calculations, suggest that DBS crystalline fibers ${ }^{[26][27]}$ arise from local stacking of molecules, which is controlled by both directional hydrogen bonds and $\pi$ stacking of aromatic rings of the benzylidene units. ${ }^{[28][29][30]}$ The role of the hydroxyl groups in the assembly process has been explored by Yamasaki and co-workers, ${ }^{[31][32]}$ who converted selec- 
tively each of the hydroxyl groups into methoxy groups. They observed that gelation was prevented only when the terminal hydroxyl group (OH6) was protected, while Rogers and coworkers[4] found that DBS derivatives lacking the benzylidene rings are poor gelators. The thermal properties of DBS gels in polar alcoholic solvents indicate that the aggregated nanofibers mainly contain DBS molecules wrapped by solvent molecules by means of hydrogen bonding. ${ }^{[33]}$ Finally, results from computer modeling of DBS monomers and dimers indicate that the self-assembly mechanism is complex and involves more than one type of interaction. [26][29]

For the first time, we report here the X-ray structure of DBS in single crystals. Additionally, X-ray diffraction (XRD) and synchrotron wide-angle $X$-ray scattering (WAXS) studies were performed for gels and xerogels, and analyzed under the light of the X-ray structural results. Also, the conformational state of the molecule in the sol state was analyzed through NMR experiments in solvents of different polarity and compared with that in the crystal state.

\section{Results and discussion}

The molecular packing of DBS molecules in their gel networks from X-ray scattering and diffraction studies

The arrangements of DBS molecules in their gel assemblies have been explored in hydrogen-bond donor and acceptor solvents ( $N$. B., ethyl acetate, isopropyl alcohol, toluene and acetone) by TEM, wide-angle X-ray scattering (WAXS) and X-ray diffraction. The gel samples were prepared by dissolving DBS at elevated temperatures and allowing them to cool to room temperature. Xerogels were obtained by evaporating the solvent at $60^{\circ} \mathrm{C}$. Also, a crystalline powder was obtained by fast cooling a solution of DBS in water (see page S19 from SI for details).
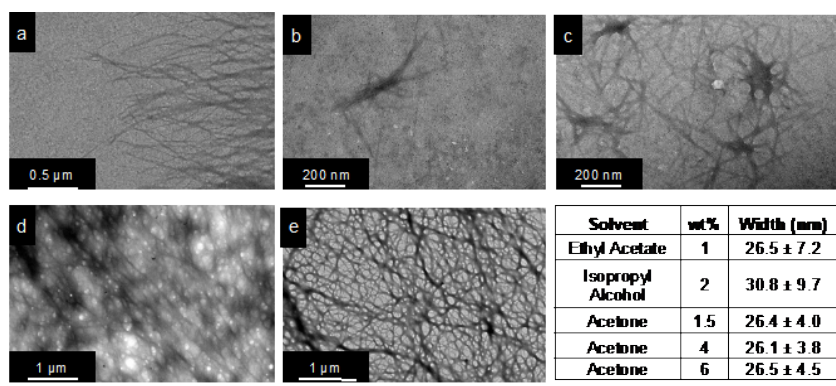

Figure 1. TEM micrographs derived from xerogels of DBS $1.5(a), 4(b)$, and $6 \mathrm{wt} \%$ (c) in acetone; $2 \mathrm{wt} \%$ in isopropyl alcohol (d); $1 \mathrm{wt} \%$ in ethyl acetate (e) and Table with fibril width from microghaphs a-e

TEM micrographs of the DBS gels in ethyl acetate, isopropyl alcohol and acetone show the formation of fibrils of similar averagewidths (25-30 nm), regardless of the DBS concentration and solvent employed (Figure 1). The WAXS profiles of DBS gels and xerogels obtained in these solvents and in toluene showed similarity in the crystalline packaging arrangements (Figure 2). The conditions under which xerogels maintain the same 3D structure as the precursor gel fibers has already been discussed in the literature. ${ }^{[35]}$
Here, the differences in shape and relative intensities of the peaks can be ascribed to crystal size changes (Figure 2). This comportment suggests that gelation by DBS (i.e., the processes in which intermolecular and new intramolecular contacts arise) are largely independent of solvent-gelator interactions, even in media for which hydrogen bonding with DBS should be quite different. This observation is in agreement with the result reported by Watase for DBS gelation in alcoholic solvents. ${ }^{[33]}$

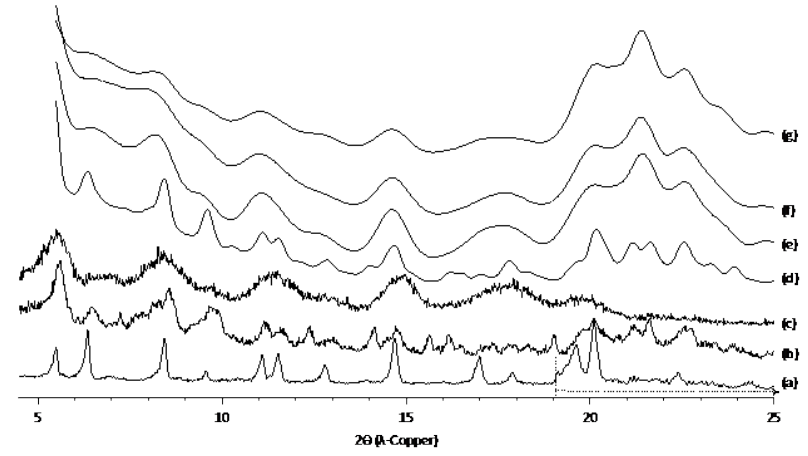

Figure 2. WAXS measurements for: (a) DBS powder; (b) an air-dried $4 \mathrm{wt} \%$ gel in acetone; (c) a $4 \mathrm{wt} \%$ gel in acetone; (d) a xerogel from toluene; (e) a xerogel from acetone; $(\mathrm{f})$ a xerogel from ethyl acetate; $(\mathrm{g})$ a xerogel from isopropyl alcohol. The intensity of the diffraction pattern in (a) was multiplied $5 \mathrm{X}$ at $>19$ degrees to facilitate comparisons

In another experiment, the WAXS of a sample, initially 4 wt\% DBS in acetone, was measured at different stages of solvent removal. To do so, the sample was left inside a capillary tube with one end open to the atmosphere for one week. Domains, formed nearer the open end, suffered relatively greater and faster loss of acetone and, thus, have higher concentrations of DBS. Optical micrographs and WAXS diffraction measurements were recorded at five positions along the capillary (Figure 3). The corresponding integrations of the 2D diffractograms into 1D profiles, after subtracting the contributions of both the capillary and residual solvent, ${ }^{[36]}$ are shown in Figure 4. The 1D diffraction patterns indicate that the structural arrangement of DBS molecules at sites 1, 2 and 3 are similar to that of the xerogels (see Figure 2 and inset in Figure 4), but are different from those at sites 4 and 5 .

At the open end of the capillary, the more rapid evaporation of acetone leads to more rapid nucleation and crystal growth. The rate of solvent loss may thus contribute to the different WAXS patterns of sites 1-3 compared with sites 4 and 5: the much slower kinetics of aggregation at the sites nearer the closed end of the capillary is a probable explanation for the different morphologies. A related phenomenon, caused by rapid and slow cooling of sol phases, has been reported in other gel systems. ${ }^{[35][37][38][39][40]}$ The more rapid crystallization (nearer the open end of the capillary) generates a molecular assembly that is like those of the gels and xerogels shown in Figure 2. 


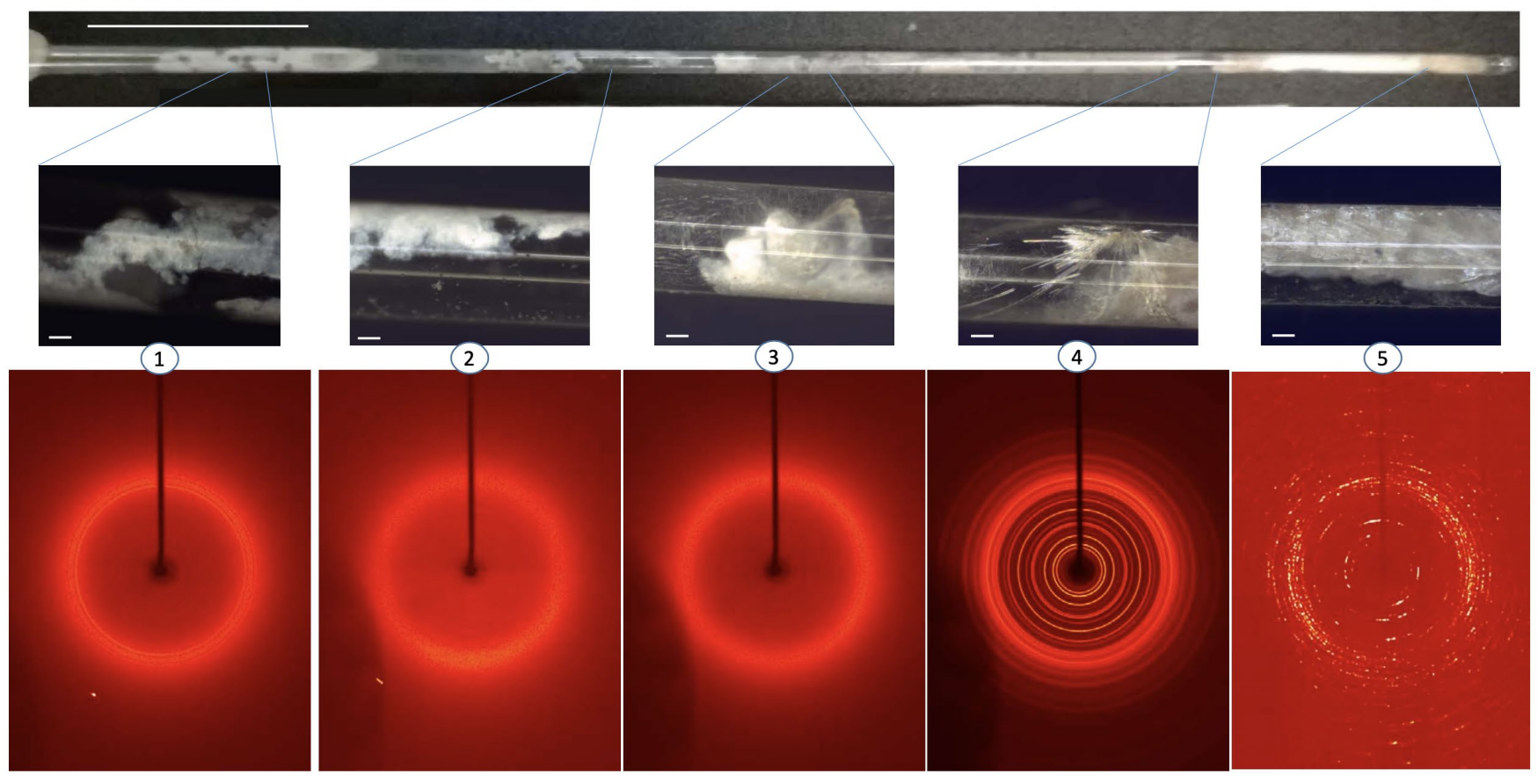

DBS gelation and crystallization inside a capillary tube: images and 2D diffraction patterns. Top: the capillary filled with 4 wt\% DBS in acetone after being exposed to air at room temperature for one week ( $1 \mathrm{~cm}$ scale bar; left, open end; right, sealed end). Middle: optical micrographs $(1 \mu \mathrm{m}$ scale bar) at the five sites where the corresponding WAXS 2D diffraction images were recorded in situ (bottom)

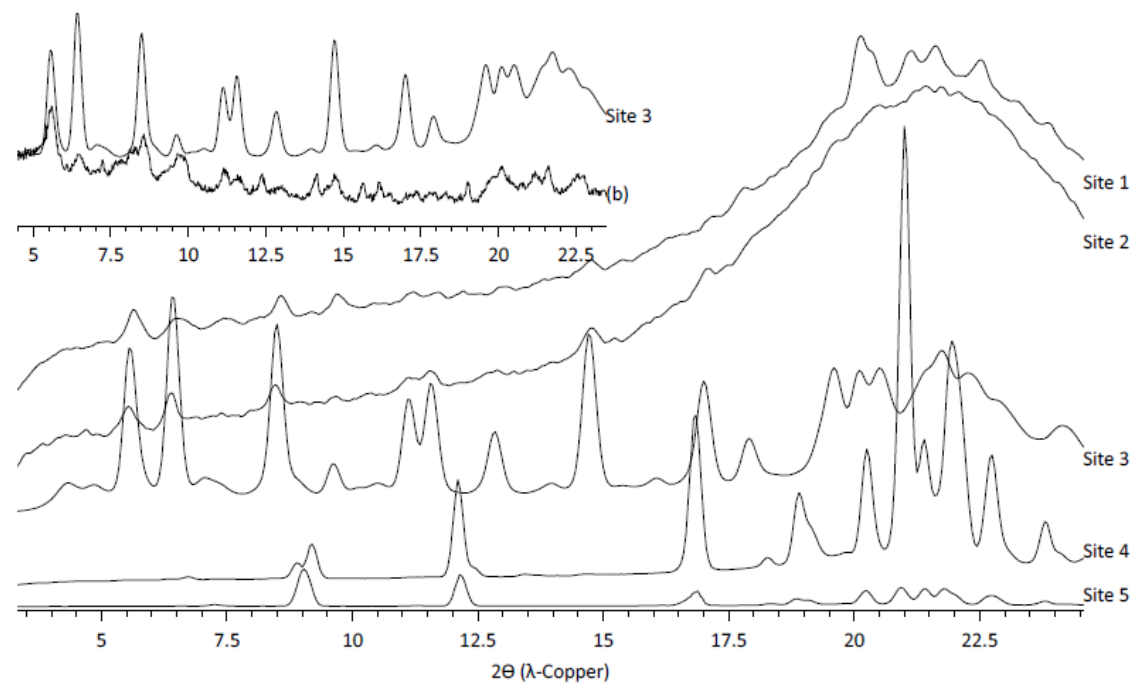

\section{X-ray diffraction analysis of the structure of DBS in a monocrystal}

Fortuitously, a single crystal of sufficient quality for X-ray analysis was obtained from site 4 in figures 3 and 4 (i.e., where aggregation and nucleation are very slow). It is worth noting that crystallization of DBS has been an elusive goal since its discovery, despite the scientific interest in its structure and applications. Analysis of this crystal structure gave definitive experimental evidence for the configuration of the benzylic carbons $\mathrm{C} 7$ and $\mathrm{C} 8$, which hold their respective phenyl rings in the equatorial disposition, as well as the existence of the butterfly-type aggregation mode.
The final refined model contains in its unit cell two symmetry-independent DBS molecules, $\mathbf{A}$ and $\mathbf{B}$, plus one water molecule (Figure 5 top and Table S8). Superposition of the two DBS molecules $\mathbf{A}$ and $\mathbf{B}$ (Figure 5 bottom) reveals that they differ slightly in the tilt angle between the phenyl rings $\left(40.2^{\circ}\right)$ and in the conformation of the C4-C6 side chain. The four 6-membered rings of DBS A and B are in chair conformations (Cremer-Pople parameters ${ }^{[41]}$ are listed in Table S7). The chair conformation favours the folding of the wings and, consequently, the intramolecular proximity of the aromatic rings. ${ }^{[42]}$ 


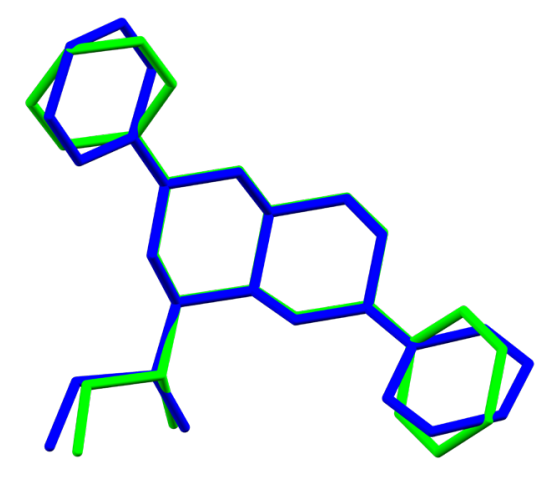

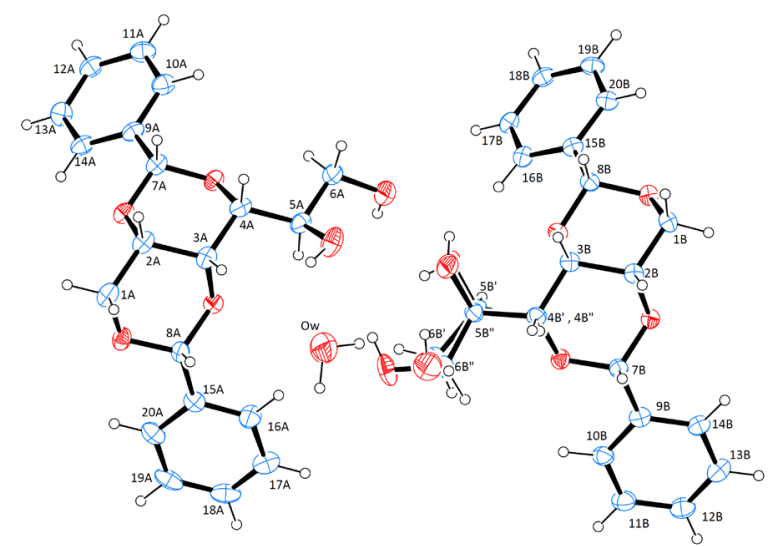

Figure 5. Top: ORTEP type diagram (ellipsoids at 50\% probability), showing the symmetry independent molecules of the refined structural. Bottom: Superposition of the two symmetry-independent molecules A (green) and $B$ (blue) by minimizing distances between homologous atoms using the program Mercury ${ }^{\circledast}$. The water molecule, the hydrogen atoms, and the disordered side chain in the unit cell were omitted to facilitate the visualization of the superposition

The C4-C6 side-chain conformations of the two independent molecules in the unit cell are slightly different. The side-chain of $\mathbf{A}$ adopts a well-defined, single conformation, with an anti-disposition of $\mathrm{H} 4$ and $\mathrm{H} 5$ as well as a synclinal-like orientation of the hydroxyl groups (type I in Scheme 2). Molecule B presents a small conformational disorder of the side-chain, although it still maintains the main features of conformation I, i.e. the anti disposition of $\mathrm{H} 4$ and $\mathrm{H} 5$ (Figure 5 bottom).

The supramolecular arrangement in the crystal reveals intermolecular van der Waals interactions and intermolecular hydrogen bonds. Symmetry-related molecules pile on top of each other forming stacks (or columns) of types $\mathbf{A}$ and $\mathbf{B}$ (Figure 6). The two stacks $\mathbf{A}$ and $\mathbf{B}$ are maintained in contact through a hydrogen bond from $\mathrm{OH} 5 \mathrm{~B}$ to $05 \mathrm{~A}$. Pairs of $\mathrm{AB}$ stacks interact laterally by van der Waals contact of the phenyl rings giving rise to $2 \mathrm{D}$ sheets. The loose packing of these sheets furnishes the final X-ray packaging. (Figure 6)

The $\mathrm{H}$-bond contacts in the hydrophilic part were assessed using PLATON ${ }^{[47]}$ and are summarized in Table 1 and Figure 6 . The clearest $\mathrm{H}$-bond is formed between the proton terminal hydroxyl $(\mathrm{OH} 6 \mathrm{~A})$ and the O5A oxygen of a neighboring DBS molecule $\mathbf{A}$ within the same stack (contact 4 in Table 1) This hydrogen bond, appears to favor stiffer packing; it occurs between ordered, symmetry-related molecules which form fibers that preferably grow in the direction of the $\mathrm{H}$-bond ( $a$ cell axis, Figure 6 ).

The water molecule participates in two $\mathrm{H}$-bonds with DBS side chain hydroxyls: one as a donor with $\mathrm{OH} 5 \mathrm{~A}$ and the other as an acceptor with $\mathrm{OH} 6 \mathrm{~B}$. Although the $\mathrm{H}$-bond angles are not optimal (125-155 ; Table 1 , entries 1-3), these interactions support the role of water as a 'bridge' between the stacks of molecules of type A and B. Finally, there is a potential $\mathrm{H}$-bond, O6A $\cdots 05 \mathrm{~B}$, that may connect directly the side chains of the two stacks. However, the angle is not optimal and it is unclear the extent to which it may contribute to the stabilization of the arrangement. This hydrogen bond network also differs from the conformation for monomeric DBS dissolved in chloroform (from NMR data; Scheme 2) in which $\mathrm{OH} 6$ interacts with the acetal oxygen $\mathrm{O} 3$ or $\mathrm{O} 4$ to form a 7- or 6membered ring.

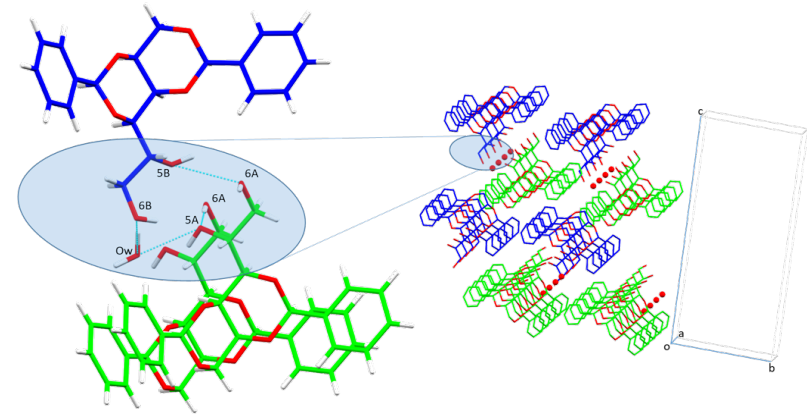

Figure 6. Crystal structure of DBS. Left: putative hydrogen bonds described in Table 2 are represented in cyan. Right: supramolecular packing of DBS in the single crystal oriented according to the unit cell

Table 1: Platon analysis of potential hydrogen bonds ${ }^{a}$

\begin{tabular}{|c|c|c|c|c|c|}
\hline Entry & H-Donor & H-Acceptor & $\begin{array}{c}\text { H"Acceptor } \\
\text { (Å) }\end{array}$ & $\begin{array}{l}\text { Donor'Ac- } \\
\text { ceptor (Å) }\end{array}$ & $\begin{array}{l}\text { Acceptor }{ }^{\prime} \mathrm{H} \cdots A c- \\
\text { ceptor }\left(\left(^{\circ}\right)\right.\end{array}$ \\
\hline 1 & $O w^{b}$ & O6B' & $1.88(6)$ & $2.63(2)$ & $134(4)$ \\
\hline 2 & $O w^{b}$ & O6B" & $1.80(7)$ & $2.69(4)$ & $155(6)$ \\
\hline 3 & $05 A^{b}$ & Ow & 2.08 & $2.66(1)$ & 125 \\
\hline 4 & $06 A^{c}$ & O5A & 1.97 & $2.81(1)$ & 179 \\
\hline 5 & O6B' & O5B' & 2.49 & $2.88(4)$ & 110 \\
\hline 6 & O6B"d & O5B" & 2.56 & 2.95(9) & 110 \\
\hline 7 & $05 B^{\prime b}$ & O6A & 2.27 & $2.90(4)$ & 132 \\
\hline
\end{tabular}

${ }^{a} d(D \cdots A)<R(D)+R(A)+0.50 ; d(H \cdots A)<R(H)+R(A)-0.12 \AA . ; D-H \cdots A>100.0$ 。

$\mathrm{b}$ intermolecular interaction.

c intermolecular interaction. Symmetry operation: $-1+x, y, z$

d intramolecular interaction 
The conformation of the DBS side chain in solution and sol state The conformation of the side-chain in the crystal state is not very different from that observed in the sol state as we determined here by NMR analysis. Our first analyses were recorded in DMSO$d_{6}$ since it is one of the few solvents in which DBS is highly soluble.

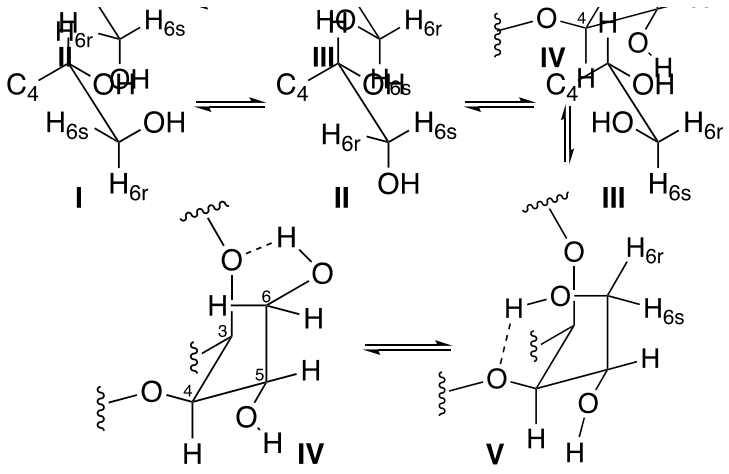

Scheme 2. Possible conformations of the C5-C6 side chain of DBS. Conformations (I, II, III) maintain $\mathrm{H} 4-\mathrm{H} 5$ in an anti-disposition. The conformations (IV, V) present the same gauche disposition about the $\mathrm{C} 4-\mathrm{C5}$ bond but have different torsional angles about the $\mathrm{C} 5-\mathrm{C} 6$ bond. Labels ' $r$ ' and ' $s$ ' refer to the pro- $R$ or pro-S configurations of $\mathrm{H} 6$ protons

The large vicinal coupling between the $\mathrm{H} 4$ and $\mathrm{H} 5$ protons $(3)_{\mathrm{HH}}=$ $9.4 \mathrm{~Hz}$, Table $2 \mathrm{~b}$ ) indicates that the conformation of the $\mathrm{C} 4-\mathrm{C} 5$ bond is locked in an anti-disposition of the two protons; DFT calculations (Table 2c) predict a value of $9.6 \mathrm{~Hz}$ for this conformation, as well as a small coupling $(2.4 \mathrm{~Hz})$ of proton $\mathrm{H} 5$ with proton $\mathrm{H} 6 \mathrm{a}$ and a medium-sized one $(4.7 \mathrm{~Hz})$ of $\mathrm{H} 5$ with $\mathrm{H} 6 \mathrm{~b}$. These values are compatible with the side chain being a mixture of two conformers in which one of the $\mathrm{H} 6$ protons switches between two gauche positions with respect to $\mathrm{H} 5$ while the other one exchanges between anti and gauche positions (i.e., either conformers I + II or II + III in Scheme 2, I being the conformation in the single-crystal of DBS; vide supra).To solve this ambiguity, long-range vicinal $\mathrm{H}-\mathrm{C}$ coupling constants were measured, ${ }^{3} \mathrm{JC}_{\mathrm{HC}}{ }^{[43]}$ yielding values of 3.3 and 1.0 Hz for C4-H6a and C4-H6b, respectively (Table 2b).

Table 2. Experimental chemical shifts (a) and coupling constants (b) of the side chain protons of DBS in several solvents and theoretical values (c) of the coupling constants are based on the Haasnoot-Altona and Bifulco equations

(a)

\begin{tabular}{|c|c|c|c|c|}
\hline$\delta(\mathrm{ppm})$ & $\mathrm{DMSO}-d_{6}$ & $\mathrm{CD}_{3} \mathrm{OD}$ & $\mathrm{C}_{3} \mathrm{D}_{6} \mathrm{O}$ & $\mathrm{CDCl}_{3}$ \\
\hline $\mathrm{H} 4$ & 3.85 & 4.03 & $3.9-4.0$ & 4.02 \\
\hline $\mathrm{H} 5$ & 3.77 & 3.98 & $3.9-4.0$ & 4.14 \\
\hline $\mathrm{H6}_{\mathrm{a}}{ }^{*}$ & 3.60 & 3.80 & 3.66 & 3.87 \\
\hline $\mathrm{H}_{6}{ }^{*}$ & 3.44 & 3.70 & 3.54 & 3.82 \\
\hline
\end{tabular}

${ }^{*}(\mathrm{a})$ and $(\mathrm{b})$ refer to the most and least deshielded protons, respectively

(b)

\begin{tabular}{|c|c|c|c|c|}
\hline${ }^{3}(\mathrm{~Hz})$ & $\mathrm{DMSO}^{-} d_{6}$ & $\mathrm{CD}_{3} \mathrm{OD}$ & $\mathrm{C}_{3} \mathrm{D}_{6} \mathrm{O}$ & $\mathrm{CDCl}_{3}$ \\
\hline $\mathrm{H} 5-\mathrm{H} 4$ & 9.4 & 10.6 & - & 7.8 \\
\hline $\mathrm{H} 5-\mathrm{H} 6_{\mathrm{a}}$ & 2.0 & 2.5 & 2.2 & 4.0 \\
\hline $\mathrm{H} 5-\mathrm{H} 6_{\mathrm{b}}$ & 5.8 & 4.7 & 4.1 & 4.7 \\
\hline $\mathrm{H} 6{ }_{\mathrm{a}}-\mathrm{C} 4$ & 3.3 & - & - & - \\
\hline $\mathrm{H} 66_{\mathrm{b}}-\mathrm{C} 4$ & 1.0 & - & - & - \\
\hline
\end{tabular}

(c)

\begin{tabular}{|c|c|c|c|c|c|}
\hline${ }^{3} J(\mathrm{~Hz})$ & I & II & III & IV & V \\
\hline $\mathrm{H} 5-\mathrm{H} 4$ & 9.7 & 9.7 & 9.5 & 2.5 & 0.8 \\
\hline $\mathrm{H} 5-\mathrm{H} 6_{\mathrm{r}}$ & 11.0 & 1.6 & 2.9 & 2.4 & 0.5 \\
\hline $\mathrm{H} 5-\mathrm{H} 6_{\mathrm{s}}$ & 3.6 & 2.3 & 10.2 & 9.9 & 4.5 \\
\hline $\mathrm{H6}_{\mathrm{s}}-\mathrm{C} 4$ & 0.6 & 4.8 & 3.9 & 4.3 & 5.2 \\
\hline $\mathrm{H}_{\mathrm{r}}-\mathrm{C} 4$ & 2.4 & 1.1 & 4.5 & 4.2 & 2.6 \\
\hline
\end{tabular}

A rotamer equilibrium $\approx 40: 60::$ :II was calculated by a least-square fitting of conformational populations to the $3 \mathrm{~J}$ couplings of the $\mathrm{H} 6$ protons with $\mathrm{H} 5$ and $\mathrm{C} 4$, using the program StereoFitter 1.0 (see Table S2 for details) and the Haasnoot-Altona ${ }^{[44]}$ and Bifulco equations ${ }^{[45][46]}$ for prediction of these couplings. Three-bond ${ }^{3} \mathrm{~J}$ couplings of $\mathrm{H} 6$ protons with $\mathrm{H} 5$ in methanol- $d_{4}$ and acetone- $d_{6}$ have similar values to those in DMSO- $d_{6}$. We interpret the similarity of the coupling constants as an indication that the conformational equilibrium is similar in the three solvents (see Figures S1-S5; S9S12; S13-S16).

The side chain scalar coupling constants in deuterated chloroform have a smaller ${ }^{3} \int_{\mathrm{H} 4, \mathrm{H} 5}$ coupling $(7.8 \mathrm{~Hz})$ and ${ }^{3} \mathrm{H}_{\mathrm{H} 6, \mathrm{H} 5}$ couplings of similar values $(4.0$ and $4.7 \mathrm{~Hz}$ ). Conformational deconvolution of these values indicates a significant contribution from either conformations IV or V; the computed conformational ratio I:II:IV/V is 35:45:20. Conformations IV and $\mathbf{V}$ allow the formation of intramolecular hydrogen bonds between the hydroxyl group at $\mathrm{C} 6$ and the acetal-oxygens $\mathrm{O} 3 / \mathrm{O} 4$, and they are expected to become more important in a non-coordinating solvent such as chloroform (see Table S2). Interaction between $\mathrm{OH} 6$ and $\mathrm{O} 3$ was considered by Knani et al. in their modeling of DBS dimers, and its importance increased when the model considered water as the solvent in place of pristine DBS. ${ }^{[29]}$ From 2D-NOESY measurements, H6b is closer to $\mathrm{H} 4$ than $\mathrm{H6a}$ in DMSO (see Figure $\mathrm{S} 8$ ); in deuterated chloroform, peak overlap precluded observation of this contact. These data lead to assignment of $\mathrm{H} 6 \mathrm{a}$ to $\mathrm{H} 6$ proS and $\mathrm{H} 6 \mathrm{~b}$ to H6proR.

The chemical shift values were more dependent on temperature in DMSO than in chloroform: in DMSO and $\mathrm{CDCl}_{3}$, respectively, the slopes in $\mathrm{ppb} / \mathrm{K}$ units were $\mathrm{OH} 5=-6.3$ and $-1.3 ; \mathrm{OH} 6=-5.9$ and 1.8. Thus, as expected, intramolecular hydrogen bonding appears to be more important in chloroform than in DMSO.

\section{Discussion}

A model to reconcile all the observations in the crystalline solid state, in gels or xerogels, and in the solution state is still missing. The solution NMR analysis reveals that the C4-C6 side chain is flexible and that its conformation is solvent dependent. Intramolecular hydrogen bonding appears to be more important in the less polar deuterochloroform than in DMSO. The structure in the monocrystal reveals the anticipated stacking of DBS molecules in the butterfly-type conformation. The supramolecular arrangement in the crystal clearly reveals a preferential mode of growing 
along the van der Waals stacked units stabilized by pi-pi interactions. Therefore, aggregation in gelation-prone systems should be strongly anisotropic, with a growing direction which leads to the formation of fibrils.

Furthermore, there are important hydrogen bond contacts in the crystal involving DBS and water molecules. It seems that incorporation of water molecules in the crystal, in combination with the flexibility of the C4-C6 side chain, relieves the energetic cost of an otherwise "rigid" packing (as it would be the stacking of identical DBS molecules, e.g. in conformation A). The existence of a second, symmetrically unrelated, conformation of DBS molecules (B) that has partial disorder of its $\mathrm{C} 4-\mathrm{C} 6$ side chain, in conjunction with the bridging water molecules, seems to favor a more elastic contact network.

Regarding the structure of DBS in gels and xerogels, experimental evidence is less conclusive. Given that the WAXS patterns in the xerogels differ from those of the single crystal, it may be anticipated that the arrangement of DBS in gels is somewhat different. The results from the experiments conducted in the capillary points to two competing packing processes: (1) gelation through crystalline fiber formation and (2) single crystal formation.

\section{Conclusions}

After nearly 130 years, the configuration and crystal structure of the important and enigmatic gelator, $(7 R, 8 S)$-1,3:2,4-dibenzylidene-D-sorbitol (DBS), has been confirmed definitively. The crystal structure shows the stacking of DBS molecules in their "butterflytype" conformation. The forces governing the molecular packing are mainly aryl/aryl and $\mathrm{H}$-bonding interactions involving DBS and water molecules. Although the 3D arrangement of DBS molecules in the crystal cannot be extrapolated directly to gel and xerogel fibers, this crystal structure demonstrates the amphiphilic and fluxional character of DBS self-association and will certainly provide a basis for future developments in the field of low-molecular organic gelators.

\section{Associated Content}

\section{Supporting Information}

Supporting information can be found in the pdf archive added to this file.

\section{Acknowledgement}

Financial support from Ministerio de Economia y Competitividad of Spain (CTQ2017-85919-R) and Xunta de Galicia (ED431D 2018/04, ED431C 2017/70 and CITACA Strategic Partnership: ED431E 2018/07)) is gratefully acknowledged. The authors thank the RIAIDT-USC analytical facilities for the use of their equipment and the ALBA Synchrotron and its staff for help with experiments performed on the BL11 beamline. ANV thanks the Conselho Nacional de Desenvolvimento Cientifico e Tecnologico (CNPq 426216/2018-0 and 311683/2019-3) of Brazil for financial support and a research fellowship and thank the Centro de Tecnologias Estratégicas do Nordeste (CETENE) for providing computational support (FACEPE APQ-1864-1.06/12). RGW thanks the US National Science Foundation for its support of the portion of the research conducted at Georgetown through grant CHE-1502856.

\section{References}

[1] J. K. Wolfe, R. M. Hann, and C. S. Hudson, "1,2,3,4Dibenzylidene-D-sorbitol," J. Am. Chem. Soc., vol. 64, no. 7, pp. 1493-1497, Jul. 1942.

[2] M. J. Meunier, "Sur les composés que la mannite et la sorbite forment avec les aldehydes," Ann. Chim. Phys., vol. 22, p. 412, 1891.

[3] V. M. Sánchez-Pedregal, M. Kertesz, R. G. Weiss, A. Navarro-Vázquez, and M. M. Cid, "NMR spectral fingerprint patterns as diagnostics for the unambiguous configurational analysis of the classic organo-gelator 1,3:2,4-dibenzylidene- sorbitol (DBS) and its derivatives," Magn. Reson. Chem., vol. 59, no. 6, pp. 608-613, Jun. 2021.

[4] A. Singh, F.-I. Auzanneau, M. G. Corradini, G. Grover, R. G. Weiss, and M. A. Rogers, "Molecular Nuances Governing the Self-Assembly of 1,3:2,4-Dibenzylidene-d-sorbitol," Langmuir, vol. 33, no. 41, pp. 10907-10916, 2017.

[5] J. M. Smith and D. E. Katsoulis, "Gelation of silicone fluids using 1,3:2,4-dibenzylidene sorbitol," J. Mater. Chem., vol. 5, no. 11, p. 1899, 1995.

[6] H. Shen, L. Niu, K. Fan, J. Li, X. Guan, and J. Song, "Application of Solubility Parameters in 1,3:2,4-Bis(3,4dimethylbenzylidene)sorbitol Organogel in Binary Organic Mixtures," Langmuir, vol. 30, no. 30, pp. 91769182, 2014

[7] A. S. Vaughan and I. L. Hosier, "The effect of dibenzylidene sorbitol on the crystallization behaviour of polyethylene," J. Mater. Sci., vol. 43, no. 8, pp. 29222928, 2007.

[8] W.-C. Lai, "The effect of self-assembled nanofibrils on the morphology and microstructure of poly(l-lactic acid)," Soft Matter, vol. 7, no. 8, p. 3844, 2011.

[9] E. A. Wilder, C. K. Hall, S. A. Khan, and R. J. Spontak, "Effects of Composition and Matrix Polarity on Network Development in Organogels of Poly(ethylene glycol) and Dibenzylidene Sorbitol," Langmuir, vol. 19, no. 15, pp. 6004-6013, 2003.

[10] M. George and R. G. Weiss, "Molecular Organogels. Soft Matter Comprised of Low-Molecular-Mass Organic Gelators and Organic Liquids," Acc. Chem. Res., vol. 39, no. 8, pp. 489-497, 2006.

[11] J. Ruíz-Olles and D. K. Smith, "Diffusion across a gel-gel interface - molecular-scale mobility of self-assembled 'solid-like' gel nanofibres in multi-component supramolecular organogels," Chem. Sci., vol. 9, no. 25, pp. 5541-5550, May 2018.

[12] K. Steck, N. Preisig, and C. Stubenrauch, "Gelling Lyotropic Liquid Crystals with the Organogelator 1,3:2,4Dibenzylidene-d-sorbitol Part II: Microstructure," Langmuir, vol. 35, no. 52, pp. 17142-17149, 2019.

[13] H. Takeno and Y. Kuribayashi, "A synchrotron small-angle X-ray scattering study on structures of 1,3:2,4dibenzylidene sorbitol gels," Colloids Surfaces $A$ Physicochem. Eng. Asp., vol. 467, pp. 173-179, 2015.

[14] Y. Lan et al., "Comparing and correlating solubility parameters governing the self-assembly of molecular gels using 1,3:2,4-dibenzylidene sorbitol as the gelator," 
Langmuir, vol. 30, no. 47, pp. 14128-14142, Dec. 2014.

[15] D. L. VanderHart, J. F. Douglas, S. D. Hudson, J. M. Antonucci, and E. A. Wilder, "NMR Characterization of the Formation Kinetics and Structure of Di-O-Benzylidene Sorbitol Gels Self-Assembled in Organic Solvents," Langmuir, vol. 27, no. 5, pp. 1745-1757, 2011.

[16] B. Kohne, K. Praefcke, R. S. Omar, and F. Frolow, "Calamitische Flüssigkristalle: Beziehung zwischen Molekülstruktur und Mesogenität, trans-und cis-1,3,5,7Tetraoxadecalin-Derivate [1,2] / Calamitic Liquid Crystals: Relationship Between Molecular Structure and Mesogenity, trans- and cis-1,3,5,7-Tetraoxad," Zeitschrift für Naturforsch. B, vol. 41, no. 6, pp. 736-750, 1986.

[17] N. Rodier, G. Ronco, R. Julien, D. Postel, and P. Villa, "2,4:3,5-Di-O-méthylène-1-p-toluènesulfonylxylitol," Acta Crystallogr. Sect. C Cryst. Struct. Commun., vol. 49, no. 11, pp. 2032-2033, 1993.

[18] S. Abramson et al., "New macromolecular host systems. Preparation and structure of certain functionalized 2,6diaryl-cis-1,3,5,7-tetraoxadecalin podand compounds and macro-m-cyclophanes," J. Chem. Soc. Chem. Commun., no. 13, p. 1611, 1994.

[19] S. Henkel, T. Leibold, and V. Jäger, "Crystal structure of(3aR,6aR)-3-[(1R,2S,3S)-1,3:2,4-di-O- ethylidene1,2,3,4-tetrahydroxy-1-butyl]-3a,6a-dihydrofuro[2,3d]isoxazole, C13H17NO6," Zeitschrift für Krist. - New Cryst. Struct., vol. 213, no. 1-4, pp. 67-68, 1998.

[20] S. Henkel, T. Leibold, and V. Jäger, "Crystal structure of(3aS,6aS)-3-[(1R,2S,3S)-1,3:2,4-di-O-ethylidene-

1,2,3,4-tetrahydroxy-1-butyl]-3a,6a-dihydrofuro[2,3-

d]isoxazole,C13H17NO6," Zeitschrift für Krist. - New Cryst. Struct., vol. 213, no. 1-4, pp. 69-70, 1998.

[21] D. A. Smith, D. Baker, and A. F. M. M. Rahman, "The first aldehyde-derived crystalline geminal diol lacking internal electronic stabilization," Struct. Chem., vol. 2, no. 1, pp. 65-70, 1991.

[22] G. Yu, X. Yan, C. Han, and F. Huang, "Characterization of supramolecular gels," Chem. Soc. Rev., vol. 42, no. 16, p. 6697, 2013.

[23] P. Terech and R. G. Weiss, "Low Molecular Mass Gelators of Organic Liquids and the Properties of Their Gels," Chem. Rev., vol. 97, no. 8, pp. 3133-3160, 1997.

[24] Z. Qi et al., "Fibrous Networks with Incorporated Macrocycles: A Chiral Stimuli-Responsive Supramolecular Supergelator and Its Application to Biocatalysis in Organic Media," Chem. - A Eur. J., vol. 19, no. 31, pp. 10150 10159, 2013.

[25] X. Du, J. Zhou, J. Shi, and B. Xu, "Supramolecular Hydrogelators and Hydrogels: From Soft Matter to Molecular Biomaterials," Chem. Rev., vol. 115, no. 24, pp. 13165-13307, Dec. 2015.

[26] E. A. Wilder, R. J. Spontak, and C. K. Hall, "The molecular structure and intermolecular interactions of 1,3:2,4dibenzylidene-D-sorbitol," Mol. Phys., vol. 101, no. 19, pp. 3017-3027, 2003.

[27] D. J. Mercurio and R. J. Spontak, "Morphological Characteristics of 1,3:2,4-Dibenzylidene Sorbitol/Poly(propylene glycol) Organogels," J. Phys. Chem. B, vol. 105, no. 11, pp. 2091-2098, 2001.
W.-C. Lai and Y.-C. Lee, "Self-assembly behavior of gels composed of dibenzylidene sorbitol derivatives and poly(ethylene glycol)," RSC Adv., vol. 6, no. 100, pp. 98042-98051, 2016.

[29] D. Knani and D. Alperstein, "Simulation of DBS, DBS$\mathrm{COOH}$, and DBS-CONHNH2 as Hydrogelators," J. Phys. Chem. A, vol. 121, no. 5, pp. 1113-1120, 2017.

[30] D. Alperstein and D. Knani, "In silico studies of 1,3(R):2,4(S)-dibenzylidene-D-sorbitol as a gelator for polypropylene," Polym. Adv. Technol., vol. 24, no. 4, pp. 391-397, 2012.

[31] S. Yamasaki, Y. Ohashi, H. Tsutsumi, and K. Tsujii, "The Aggregated Higher-Structure of 1,3: 2,4-Di- O benzylidene-D-sorbitol in Organic Gels," Bull. Chem. Soc. Jpn., vol. 68, no. 1, pp. 146-151, Jan. 1995.

[32] S. Yamasaki and H. Tsutsumi, "The Dependence of the Polarity of Solvents on 1,3 : 2,4-Di- O -benzylidene-Dsorbitol Gel," Bull. Chem. Soc. Jpn., vol. 68, no. 1, pp. 123127, Jun. 1995.

[33] M. Watase, Y. Nakatani, and H. Itagaki, "On the Origin of the Formation and Stability of Physical Gels of Di-Obenzylidene-d-sorbitol," J. Phys. Chem. B, vol. 103, no. 13, pp. 2366-2373, 1999.

[34] J. Kern et al., "Room temperature femtosecond X-ray diffraction of photosystem II microcrystals," Proc. Natl. Acad. Sci. U. S. A., vol. 109, no. 25, pp. 9721-9726, Jun. 2012.

[35] M. George, G. Tan, V. T. John, and R. G. Weiss, "Urea and Thiourea Derivatives as Low Molecular-Mass Organogelators," Chem. - A Eur. J., vol. 11, no. 11, pp. 3243-3254, 2005.

[36] E. Ostuni, P. Kamaras, and R. G. Weiss, "Novel X-ray Method for In Situ Determination of Gelator Strand Structure: Polymorphism of Cholesteryl Anthraquinone2-carboxylate," Angew. Chemie Int. Ed. English, vol. 35, no. 12, pp. 1324-1326, 1996.

[37] X. Huang, S. R. Raghavan, P. Terech, and R. G. Weiss, "Distinct Kinetic Pathways Generate Organogel Networks with Contrasting Fractality and Thixotropic Properties," J. Am. Chem. Soc., vol. 128, no. 47, pp. 15341-15352, 2006.

[38] X. Huang, P. Terech, S. R. Raghavan, and R. G. Weiss, "Kinetics of $5 \alpha$-Cholestan-3 $\beta$-ylN-(2Naphthyl)carbamate/n-Alkane Organogel Formation and Its Influence on the Fibrillar Networks," J. Am. Chem. Soc., vol. 127, no. 12, pp. 4336-4344, 2005.

[39] X. Y. Liu and P. D. Sawant, "Mechanism of the Formation of Self-Organized Microstructures in Soft Functional Materials," Adv. Mater., vol. 14, no. 6, pp. 421-426, 2002.

[40] R. Yu, N. Lin, W. Yu, and X. Y. Liu, "Crystal networks in supramolecular gels: formation kinetics and mesoscopic engineering principles," CrystEngComm, vol. 17, no. 42 pp. 7986-8010, 2015.

[41] D. Cremer and J. A. Pople, "General definition of ring puckering coordinates," J. Am. Chem. Soc., vol. 97, no. 6, pp. 1354-1358, 1975.

[42] A. J. Neel, M. J. Hilton, M. S. Sigman, and F. D. Toste, "Exploiting non-covalent $\pi$ interactions for catalyst design," Nature, vol. 543, no. 7647, pp. 637-646, Mar. 2017. 
[43] J. Saurí, P. Nolis, and T. Parella, "How to measure longrange proton-carbon coupling constants from $1 \mathrm{H}$ selective HSQMBC experiments," Magn. Reson. Chem., vol. 58, no. 5, pp. 363-375, 2019.

[44] C. A. G. Haasnoot, F. A. A. M. de Leeuw, and C. Altona, "The relationship between proton-proton NMR coupling constants and substituent electronegativities-I," Tetrahedron, vol. 36, no. 19, pp. 2783-2792, 1980.

[45] G. Palermo, R. Riccio, and G. Bifulco, "Effect of Electronegative Substituents and Angular Dependence on the Heteronuclear Spin-Spin Coupling Constant
3JC-H: An Empirical Prediction Equation Derived by Density Functional Theory Calculations," J. Org. Chem., vol. 75, no. 6, pp. 1982-1991, 2010.

[46] A. Navarro-Vázquez, R. Santamaría-Fernández, and F. J. Sardina, "MSpin-JCoupling. A modular program for prediction of scalar couplings and fast implementation of Karplus relationships," Magn. Reson. Chem., vol. 56, no. 6, pp. 505-512, 2017.

[47] A. L. Spek, "Single-crystal structure validation with the program PLATON," J. Appl. Crystallogr., vol. 36, no. 1, pp. 7-13, Feb. 2003. 